\title{
The Radiological Images and the Diagnostic of COVID-19
}

\author{
Cesar Augusto de Araújo Neto ${ }^{1^{*}}$ \\ ${ }^{1}$ Director of Image Memorial Diagnosis, Associate Professor of Internal Medicine and Diagnostic Support, Medicine School, \\ Federal University of Bahia; Salvador, Bahia, Brazil
}

The gold-standard method to identify the presence of COVID-19 is the RT-PCR. However, the imaging diagnostic has been requested when there is suspicion of disease's presence and/or the inflammatory phase of the disease begins. Ths artices described the most common manifestations and patterns of lung abnormality on computed X-Ray (CXR), computer tomography (CT) and Ultrasound of the chest in COVID-19. Notwithstanding the RT-PCR is the gold-standard diagnostic method for COVID-19, the CT has been shown an essential tool to identify pneumonia and the complications of COVID-19 in a patient. This review article aimed to summarize the radiological findings of COVID-19 researches for the following three principal areas: (1) radiological performance in the detection of COVID-19; (2) radiological role in the diagnosis of COVID-19; and (3) radiological function in the monitoring of COVID-19. We searched the articles in the main database (PubMed/Medline, Elsevier Science Direct, Scopus, Isi Web of Science, Embase, Exerpta Medica, UptoDate, Lilacs, Novel Coronavirus Resource Directory from Elsevier), in the high-impact international scientific Journals (Scimago Journal and Country Rank - SJR - and Journal Citation Reports - JCR), such as The Lancet, Science, Nature, The New England Journal of Medicine, Physiological Reviews, Journal of the American Medical Association, Plos One, Journal of Clinical Investigation, and in the data from Center for Disease Control (CDC), National Institutes of Health (NIH), National Institute of Allergy and Infectious Diseases (NIAID) and World Health Organization (WHO). We prior selected meta-analysis, systematic reviews, article reviews and original articles in this order. We reviewed 121 articles and used 57 for this paper from March to May 2020, using the terms coronavirus, SARS-CoV-2, novel coronavirus, Wuhan coronavirus, severe acute respiratory syndrome, 2019-nCoV, 2019 novel coronavirus, n-CoV-2, covid, n-Sars-2, COVID-19, corona virus, coronaviruses, diagnostic, radiology, imaging, computed tomography, chest, CT, X-Ray, with the tools MeSH (Medical Subject Headings), AND, OR, and characters [,,,$; \%$, to ensure the best review topics. We concluded that the imaging method to detect the features of COVID-19 plays an important role in the diagnosis and follow up of the patient with COVID-19 pneumonia. Despite CT has a better sensitivity when compared to CRX and ultrasound, the portable CRX and portable ultrasound could be a new tool with minimal risk of contamination and with good sensitivity.

Keywords: COVID-19. SARS-COV-2. Diagnostic. CT. X-Ray. Lungs. Groud-Glass Opacity.

\section{Introduction}

Since the spread of COVID-19 last December, chest imaging has been of great importance for the diagnosis and management of patients with COVID-19 infection [1], since the infection can lead to severe acute respiratory syndrome (SARS) and death in a short amount of time. Some image methods are currently being used to

Received on 2 March 2020; revised 9 June 2020.

Address for correspondence: ISI-SENAI CIMATEC. Av. Orlando Gomes, 1845, Piatã. Zip Code: 41650-010. Salvador, Bahia, Brazil. E-mail: caaneto@gmail.com.

J Bioeng. Tech. Appl. Health (D) 2020 by SENAI CIMATEC. detect the abnormalities of pneumonia caused by COVID-19, such as computed tomography (CT) or high resolution computed tomography (HRCT), computed X-Ray (CRX) and ultrasound (US), to help in the diagnosis and in the management of the patient [2]. Moreover, it also important to know how it manifests in the lungs, the location of the lesions, the progression of the disease and the abnormalities that can be present in the lungs [3]. A deep understanding of image methods is essential in order to determine which are good options to use, and how to look for the abnormalities found in infected patients with COVID-19. That is one of the key components in the diagnosis of patients with suspected infection so as to secure the best possible outcome for them $[4,5]$. 
The objective of this review is to present the main image methods for COVID-19 detection and the pulmonary findings observed in the disease through the images of the reviewed studies.

\section{Main Findings in Chest Images of COVID-19}

The typical radiological characteristics in COVID-19 pneumonia involve bilateral, multifocal, multilobar ground-glass opacity (GGO) with patchy consolidations, a peripheral/ subpleural, or posterior distribution (or both), principally in the lower lobes (Figure 1) [1-25]. GGO occurs in multiple interstitial and alveolar processes maintaining the bronchial and vascular margins [26], while consolidation is a region of opacification, which obscures the bronchial and vascular margins [27]. GGO or GGO with consolidation was the most frequent radiological features in COVID-19 pneumonia. Other typical radiological characteristics incorporate interlobular septal thickening, crazy-paving pattern, air bronchogram/traction bronchiectasis, halo sign/reverse halo sign, peripheral/subpleural involvement, and pleural thickening $[1,2,5$, $7-9,12,14,17,19-21,24,26]$. In the literature, tuncommon findings are: pulmonary emphysema, pneumothorax, pleural effusion, pericardial effusion, lymphadenopathy, cavitation, and are uncommon findings $[1,5,8]$.

Li and colleagues [28], summarized the findings in chest computer tomography (CT) as following:

1. Ground-glass opacities (GGO) $(100 \%$ of the cases);

2. GGO pattern;

3. GGO location;

4. Consolidation;

5. Multilobe involvement;

6. Bilateral distribution;

7. Location of consolidation or GGO;

8. Pulmonary nodules surrounded by GGO;

9. Interlobular septal thickening;

10. Air bronchogram;

11. Halo sign;

12. Presence of cavitation;
13. Bronchial wall thickening;

14. Bronchiectasis;

15. Perilesional vessel diameter;

16. Lymphadenopathy (defined as lymph node with short-axis $>10 \mathrm{~mm}$ );

17. Pleural effusion; and

18. Pericardial effusion.

Based on a several images studies, the American College of Radiology, Society of Thoracic Radiology, and Radiological Society of North America Radiology categorized the main findings of COVID-19 chest CT images as typical, indeterminate and atypical features, and negative for pneumonia) [29,30]. The typical features are peripheral bilateral GGOs, rounded GGOs, and reverse halo sign of organizing pneumonia. Indeterminate features diffuse, perihilar, or unilateral GGOs with nonrounded, nonperipheral distribution. Atypical features include isolated consolidations, treein-bud opacities, cavitation, and smooth interlobular septal thickening with pleural effusion (Table 1). Regarding the phase of the disease, Pan and colleagues [4] divided the progression of chest abnormalities/disease in 4 phases: early phase, progressive phase, severe phase, and dissipative phase (Table 2). Additionally, there are specific placements for abnormalities on the chest that can common occur in COVID-19 patients (Table 3) [31]. Zhang (2020) [32] observed $95.40 \%$ of the lesions caused by COVID-19 are in the middle and lower part of the lung, while $4.60 \%$ is in the upper part of the lung. The same author introduced a CT imaging score system to quantify the pathological changes in the lungs of patients with COVID-19 (Table 4).

\section{Computer Tomography (CT) High Resolution}

In addition to computed X-Rays, computed tomography (CT) is also able to show the main finding (GGO) in COVID-19 pneumonia. Highresolution CT (HR-CT) especially plays an important role in the early diagnosis of COVID-19 disease infection $[28,37,38]$ due to a higher 
Figure 1. CT scans in a patient with COVID-19 pneumonia.
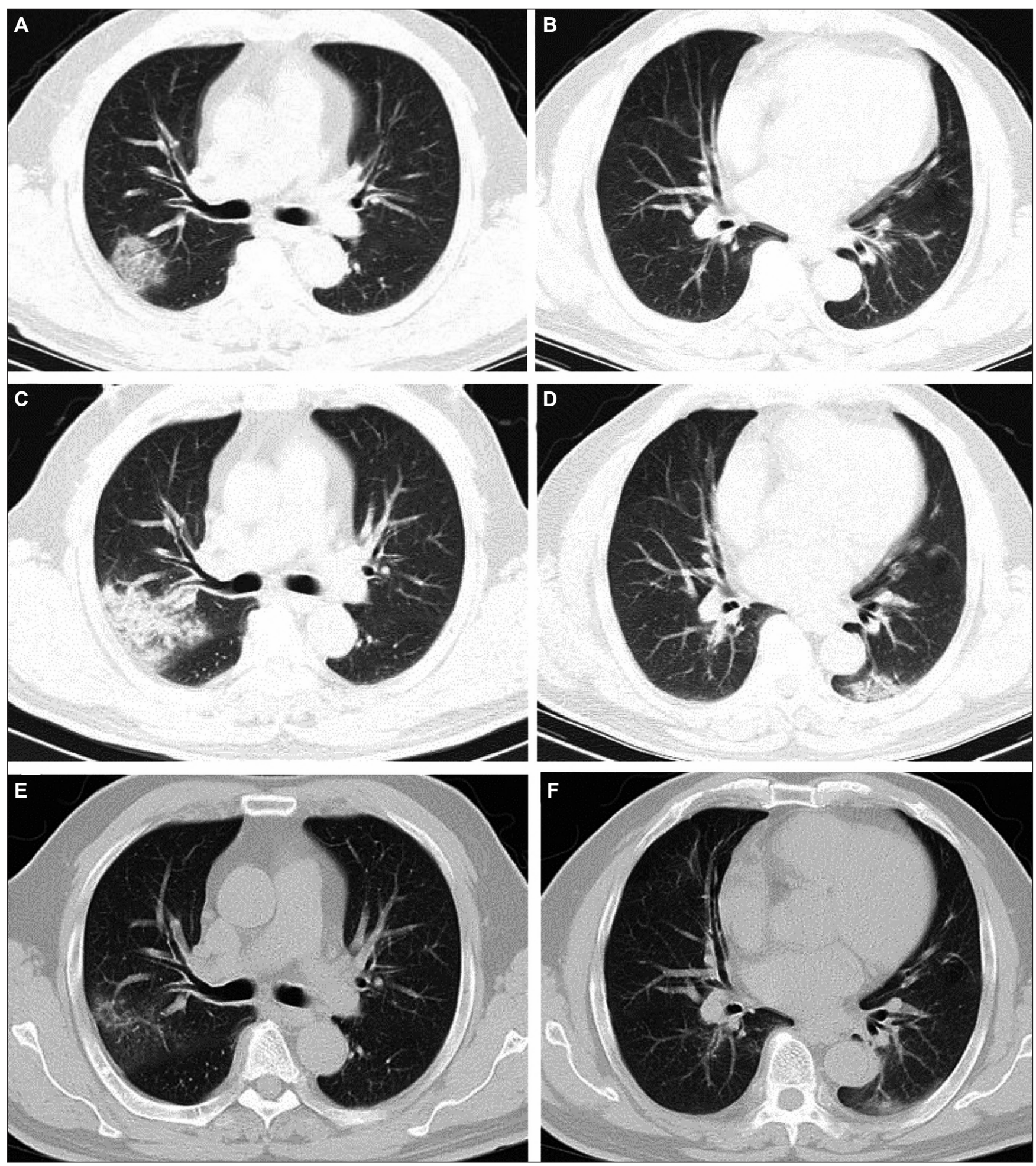

A, B, Scan obtained on illness days 2 showed ground-glass opacity with intralobular septal thickening (crazy-paving pattern) that affected posterior segment of right upper lobe. C, D, Scan obtained on illness days 8 showed increased consolidative opacities. Note that patchy ground-glass opacity newly developed in left lower lobe. E, F, Scan obtained on illness days 13 showed absorption of abnormalities, with pure ground-glass opacity left in the posterior segment of right upper lobe and posterior basal segment of left lower lobe.

Source/Credit: Wu and Wang [1]. 
Table 1. Chest CT findings related to COVID-19 (expert consensus by Society of Thoracic Radiology, and Radiological Society of North America Radiology [30].

\begin{tabular}{|c|c|c|c|}
\hline Classification & Rationale & CT findings & Suggested reported language \\
\hline Typical & $\begin{array}{l}\text { Commonly reported } \\
\text { imaging features of } \\
\text { greater for specificity } \\
\text { for COVID-19 } \\
\text { pneumonia }\end{array}$ & $\begin{array}{l}\text { Peripheral, bilateral } \\
\text { (multilobar) GGO*, } \\
\text { consolidation, or visible } \\
\text { intralobular lines }\end{array}$ & $\begin{array}{l}\text { Commonly reported imaging features of } \\
\text { COVID-19 pneumonia are present }\end{array}$ \\
\hline Indeterminate & $\begin{array}{l}\text { Nonspecific imaging } \\
\text { features of COVID-19 } \\
\text { pneumonia }\end{array}$ & $\begin{array}{l}\text { Multifocal, perihilar, } \\
\text { unilateral GGO or } \\
\text { nonrounded or } \\
\text { nonperipheral }\end{array}$ & $\begin{array}{l}\text { Imaging features can be seen with COVID-19 } \\
\text { pneumonia }\end{array}$ \\
\hline Atypical & $\begin{array}{l}\text { Uncommonly or not } \\
\text { reported features of } \\
\text { COVID-19 pneumonia }\end{array}$ & $\begin{array}{l}\text { Isolated lobar or } \\
\text { segmental consolidation, } \\
\text { discrete small nodules, } \\
\text { cavitation or interlobular } \\
\text { septal thickening, pleural } \\
\text { effusion }\end{array}$ & $\begin{array}{l}\text { Imaging features are atypical or uncommonly } \\
\text { reported for COVID- } 19 \text { pneumonia, an } \\
\text { alternative diagnosis should be considered }\end{array}$ \\
\hline Negative & No features of pneumonia & $\begin{array}{l}\text { No CT features to } \\
\text { suggest pneumonia }\end{array}$ & No CT findings indicate pneumonia \\
\hline
\end{tabular}

*GGO: Ground-glass opacities.

Source/Credit: Akçay and colleagues [30].

Table 2. Phase and findings in Chest CT-COVID-19 patients.

\begin{tabular}{|c|c|c|}
\hline Phase & CT Finding & Figure \\
\hline Early (0-4 days) & $\begin{array}{l}\text { Single or multiple lesions distributed along with the subpleural areas or bronchi } \\
{[33,34] \text {. Presence of nodular or patchy GGOs }[30] \text {, with the blood vessels seen }} \\
\text { thickening and passing through the GGO }[12,35] \text {. }\end{array}$ & Figure 2 \\
\hline $\begin{array}{l}\text { Progressive } \\
(5-8 \text { days })\end{array}$ & $\begin{array}{l}\text { The number of lesions increased significantly. Original lesions are partially absorpted } \\
\text { and new lesions with GGOs and the consolidations coexisted }[7,36] \text {. Presence of } \\
\text { distortion of local lung structures, bronchodilation, and focal atelectasis. }\end{array}$ & Figure 3 \\
\hline Severe (9-13 days) & $\begin{array}{l}\text { Bilateral lesions with diffuse infiltration of all segments of the lungs, and manifesting } \\
\text { as "white lung." Air bronchograms suggested a large amount of cellular exudation in } \\
\text { the alveolar cavity. Subsegmental atelectasis or reduction of lung volume was } \\
\text { sometimes noted, and a small amount of pleural fluid could be seen bilaterally. } \\
\text { Currently appears around } 14 \text { days after the onset of the disease, but in some cases } \\
\text { developed rapidly [37, 38]. }\end{array}$ & Figure 4 \\
\hline $\begin{array}{l}\text { Dissipate } \\
\text { ( } \geq 14 \text { days after } \\
\text { the onset of the } \\
\text { initial symptom) }\end{array}$ & $\begin{array}{l}\text { Gradual absorption of the lesions, leaving a few cord-like high-density shadows, } \\
\text { indicative of fibrosis. This phase happens commonly after } 14 \text { days [28]. }\end{array}$ & Figure 5 \\
\hline
\end{tabular}

Source/Credit: Li and colleagues (adapted) [28].

sensitivity (98\%) [39] compared with other images methods.

The HR-CT allows for an evaluation of lesions in the lungs, and, combined with clinical manifestations and laboratory diagnosis, such as RT-PCR, can confirm COVID-19 diagnosis and instruct the management of the patient in the early stage of the disease. In cases when the laboratory test is negative but the physician is suspicious of COVID-19 infection, the performance of an HR-CT is important because abnormalities in the lungs are present in the early stage of the disease sometimes [40, 41]. However, it is important to be aware of the radiation of $\mathrm{CT}$. If the patient 
Table 3. Main location findings in the chest of COVID-19 patient [31].

\begin{tabular}{|c|c|c|c|c|c|c|c|}
\hline Phase & AbnL & GGO & Co & CPP & $\mathbf{P E}$ & $\mathrm{Ca}$ & $\mathbf{L}$ \\
\hline Early & $\begin{array}{l}\text { Lower lobes } \\
\text { unilaterally or } \\
\text { bilaterally }\end{array}$ & Yes & Sometimes & No & No & No & No \\
\hline Progressive & $\begin{array}{l}\text { Bilateral multilobe } \\
\text { distribution }\end{array}$ & Yes & Sometimes & Yes & Sometimes & No & No \\
\hline Severe* & $\begin{array}{l}\text { Bilateral multilobe } \\
\text { distribution }\end{array}$ & Yes & Yes & Yes & Yes & Sometimes & Sometimes \\
\hline $\begin{array}{l}\text { Dissipate/ } \\
\text { Absorption }\end{array}$ & Bilateral & $\begin{array}{c}\text { Sometimes } \\
\text { (as a demonstration } \\
\text { of the absorption) }\end{array}$ & Sometimes & No & No & No & No \\
\hline
\end{tabular}

AbnL: abnormalities location; GGO: groud-glass opacity; Co: consolidation; CPP: crazy-paving pattern; PE: pleural effusion; Ca: cavitation; L: lymphadenopathy. *Presence of residual parenchymal bands.

Figure 2. Patient with coronavirus disease (COVID-19) pneumonia in the early stage.

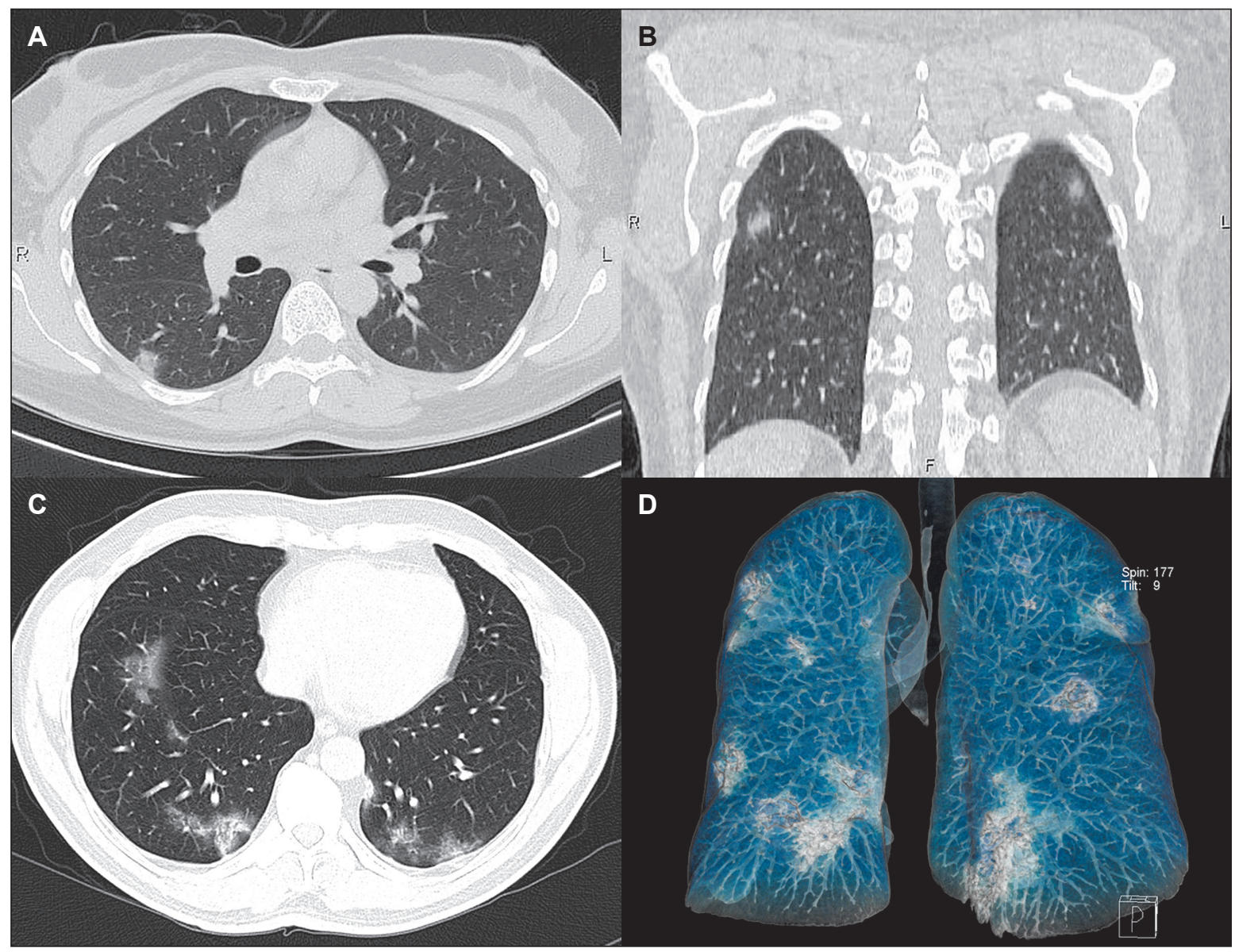

A. Axual reconstruction. B. Coronal reconstruction. Several small patchy ground glass opacities and consolidations are scattered at both lungs more prominent at subpleural regions (CT images). C. Axial reconstruction. B. Coronal reconstruction. CT demonstrates multilobar and bilateral ground-glass opacities with rounded morphology, mostly in the periphery of both lungs. Source/Credit: A-B: Radiopaedia - Case courtesy of Dr Mohammad Taghi Niknejad, <a href="https://radiopaedia. org/">Radiopaedia.org $</ a>$. From the case $<$ a href="https://radiopaedia.org/cases/75829">rID: 75829</a $>$. C-D: Case courtesy of Dr Antonio Rodrigues de Aguiar Neto, $<$ a href="https://radiopaedia.org/" $>$ Radiopaedia.org $</ a>$. From the case $<\mathrm{a}$ href="https://radiopaedia.org/cases/77010">rID: 77010</a> 
Figure 3. Patient with COVID-19 pneumonia (progressive phase).
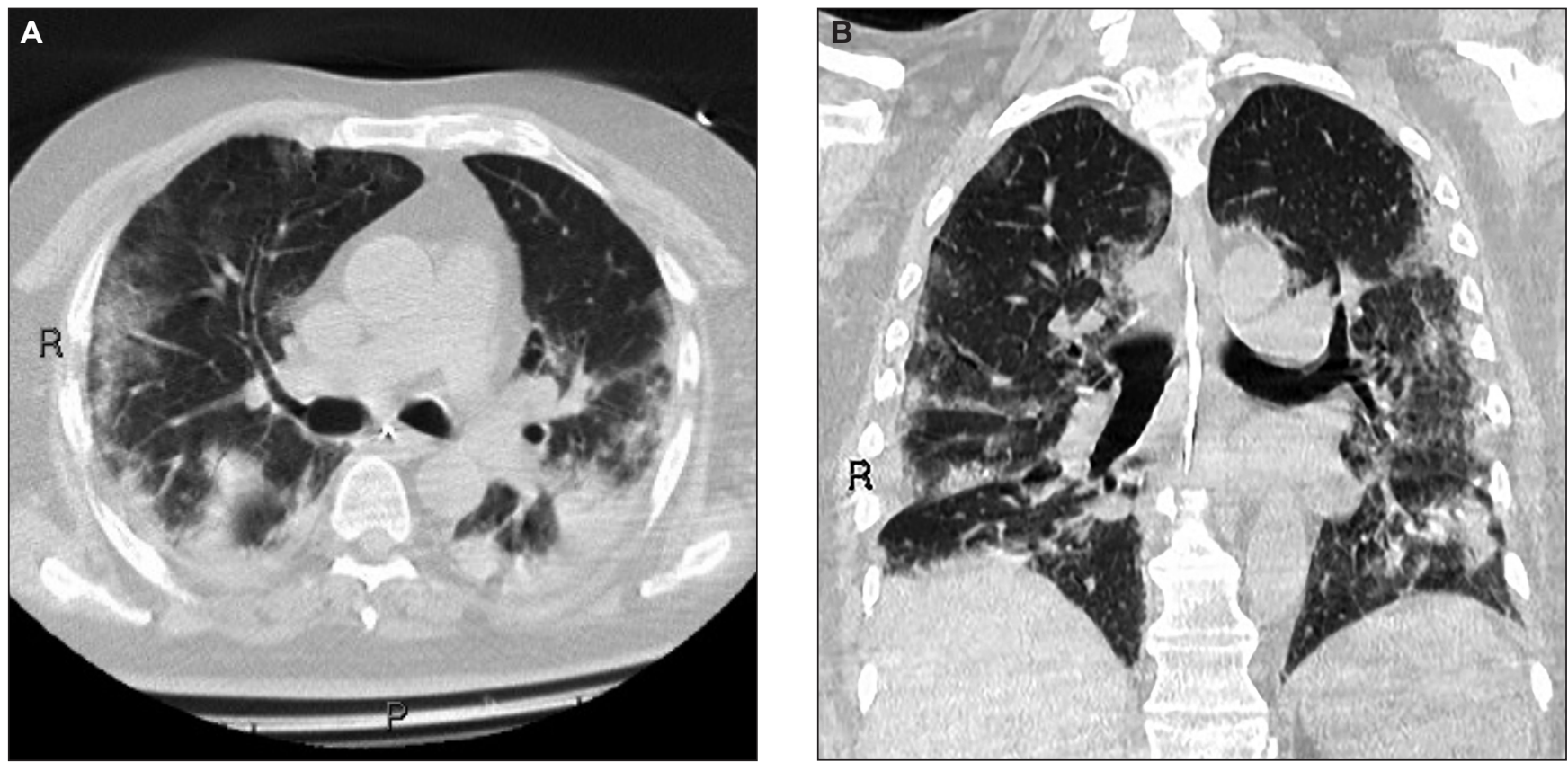

A. Axial reconstruction. Multifocal regions of consolidation and ground-glass opacifications. These have a peripheral and basal predominance. No pleural or pericardial effusion. B. Coronal reconstruction. Source/Credit: Li and colleagues [28].

Figure 4. Patient with coronavirus disease (COVID-19) pneumonia (severe phase).

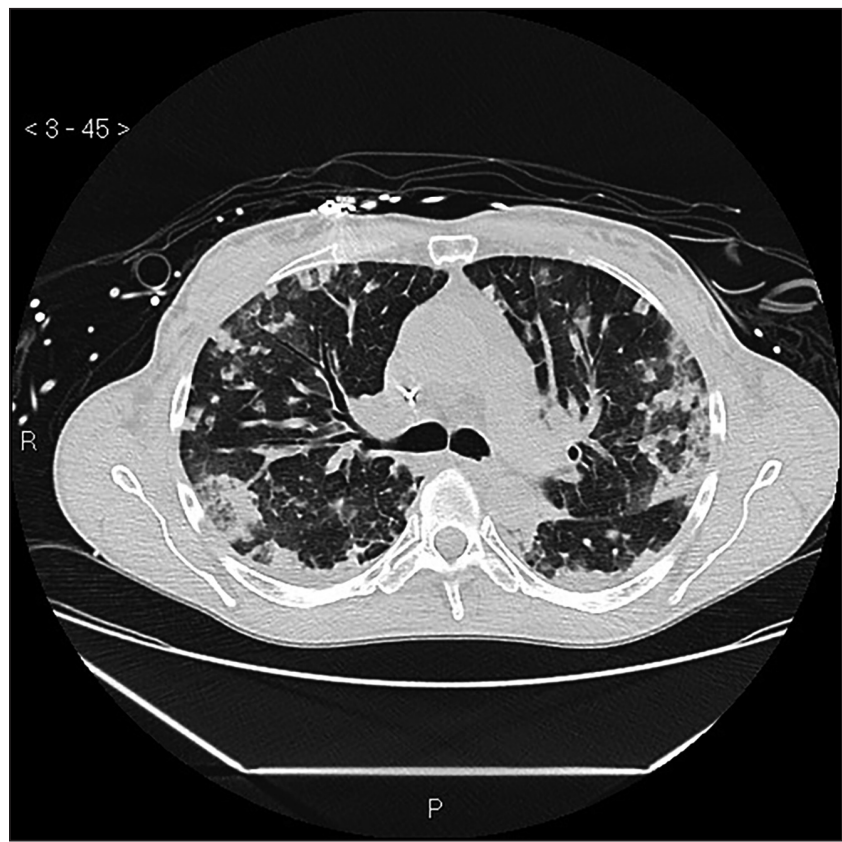

Axial reconstruction. Diffuse bilateral coalescent opacities and groundglas opacities, mediastinal lymphadenomatosis.

Source/Credit: Case courtesy of Dr Sajoscha Sorrentino, $<\mathrm{a}$ href="https://radiopaedia.org/" $>$ Radiopaedia.org $</ \mathrm{a}>$. From the case $<$ a href="https://radiopaedia.org/cases/16290">rID: 16290</a>.
Figure 5. Patient with coronavirus disease (COVID-19) pneumonia in dissipative phase.

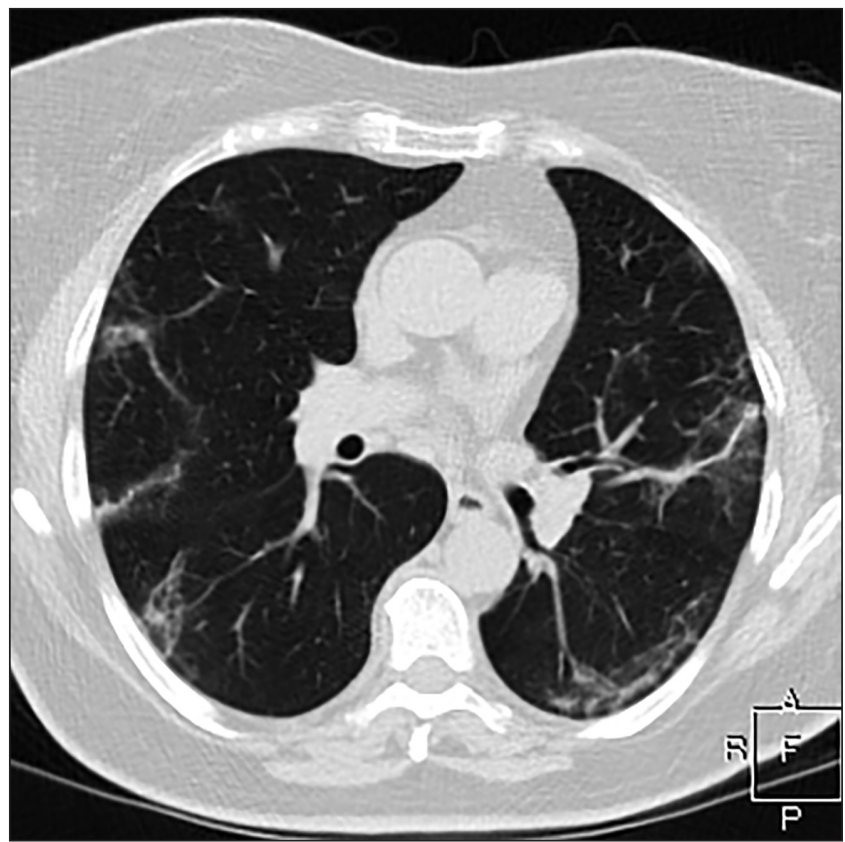

Transforming ground-glass opacity to subpleural fibrous stripes. Source/Credit: Case courtesy of Dr Vitalii Rogalskyi, <a href="https://radiopaedia.org/" $>$ Radiopaedia.org $</ a>$. From the case $<$ a href="https://radiopaedia.org/cases/76319">rID: 76319</ a> 
Table 4. CT imaging score system to quantify the severity of pneumonia in the COVID-19 patients.

\begin{tabular}{clc}
\hline Number & Performance & Score \\
\hline 1 & $\begin{array}{l}\text { Unbilateral patchy shadow or } \\
\text { ground-glass opacity }\end{array}$ & 5 \\
2 & $\begin{array}{l}\text { Bilateral patchy shadow or } \\
\text { ground-glass opacity }\end{array}$ & 7 \\
3 & Diffuse changes for (1) or (2) & 2 \\
4 & Unbilateral solid shadow, striped shadow & 2 \\
5 & Bilateral solid shadow, striped shadow & 4 \\
6 & Unbilateral pleural effusion & 2 \\
7 & Bilateral pleural effusion & 4 \\
8 & Increased or enlarged mediastinal & 1 \\
& lymph nodes & \\
\hline
\end{tabular}

Source/Credit: Zhang Z. (2020) [32].

does not show clinical symptoms or has an RTPCR negative but the physician suspects it is a COVID-19 case, an initial X-Ray could be satisfactory $[32,40,41]$.

\section{Imaging Phases of COVID-19}

In the early phase of COVID-19, when the patient exhibits moderate clinical symptoms or no clinical symptom (Table 3 ), the chest CT could show nodular-shape-lesions (single or multiple) or patchy GGOs, indicating the spread of the disease with the invasion of the bronchioles and alveolar epithelium of the cortical lung tissues [5]. It could be followed by the thickening of interlobular and intralobular septa, and the appearance of halo signs around the nodules. The pathological basis may be congestion of alveolar septal capillaries, exudation of fluid into the alveoli, and interstitial edema of the interlobular septum $[5,4,41]$

In the progressive phase, the number of lesions increased, the GGOs and the consolidations coexisted due to the amount of cellular exudate accumulated in the alveolar cavity, which cause interstitial vasodilation and exudation, and fusion of alveoli. The "crazy paving appearance" is presented reflecting interstitial lesions [28].

In the severe phase, the lesions are bilateral with diffuse infiltration of all lungs' segments, with the apparency of "white lung." A large amount of cellular exudation suggests air bronchograms in the alveolar cavity. Also, subsegmental atelectasis or decrease of lung volume, as well as a small quantity of pleural fluid could be seen bilaterally. The clinical symptoms were compatible with the severe nature of clinical manifestations. Nevertheless, unlike SARS, the appearance of both pneumomediastinum and subcutaneous gas was uncommon [5, 37, 38]. The dissipative phase is similar early phase or presents gradual absorption of the lesions, leaving a few cord-like high-density shadows [5].

The dissipative phase is like the early phase or shows gradual absorption of the lesions, leaving a few cord-like high-density shadows [5].

\section{The Role of Chest X-Rays in COVID-19}

Bhat and colleagues [31] demonstrated that the value of computed chest X-Ray (CRX) is relatively low $(30 \%-60 \%)$ in COVID-19 pneumonia [42], indicating that a normal chest X-Ray cannot exclude the presence of abnormalities in lung patients of COVID-19, especially in the early stages (Figure 6) [31, 42, 43]. For this reason, non-contrast chest CT is considered best for early diagnosis of viral disease in suspected patients with normal chest X-Ray [11, 44]. However, CXRs remain the initial imaging tool of choice but have a limited role in the diagnosis of the disease [31].

About the main findings, Wong and colleagues [45] found that consolidation was the most common finding on CXRs in COVID-19 patients with a peripheral, lower zone predominance.

Despite CT's higher sensitivity when compared to other imaging methods, the issue lies in the transportation of the patient to the CT room. It is especially difficult for Intensive Care Unit (ICU) patients, for children and pregnant women due to the ionizing radiation, not to mention the risk of contamination to healthcare workers during the transportation and management of the infected patient. So, since infection control 
issues associated with patient transportation to $\mathrm{CT}$ rooms, the difficulties concerning $\mathrm{CT}$ room decontamination, and the absence of CT available in parts of the world, the portable chest radiography (CXR) is a possible method for identification and follow up of lung abnormalities [31].

\section{$\underline{\text { Portable CXR }}$}

According to Jacobi and colleagues [46], patterns of COVID-19 lung disease can be identified by conventional chest radiography, besides the goldstandard image methods is the chest CT. The grade of the disease's severity is based on the percentage of lung involvement. So portable CXR will widespread availability and reduced infection control issues that currently limit CT utilization [46, 47].

Also, groud-glass densities observed on CT may often have a correlation that is difficult to detect on portable CXR (Figure 7). Often, reticular opacities following regions of ground-glass attenuation are more easily detectable on standard CXR (Figure 8). The obscure pulmonary opacities on CXR can sometimes be diffuse, causing the identification of the features a challenge for some clinicians (Figure 9) [46, 47].

Neri and colleagues [48] in a study about $\mathrm{CT}$ and artificial intelligence presented the

Figure 6. Patient with COVID-19 pneumonia (CRX and CT images).

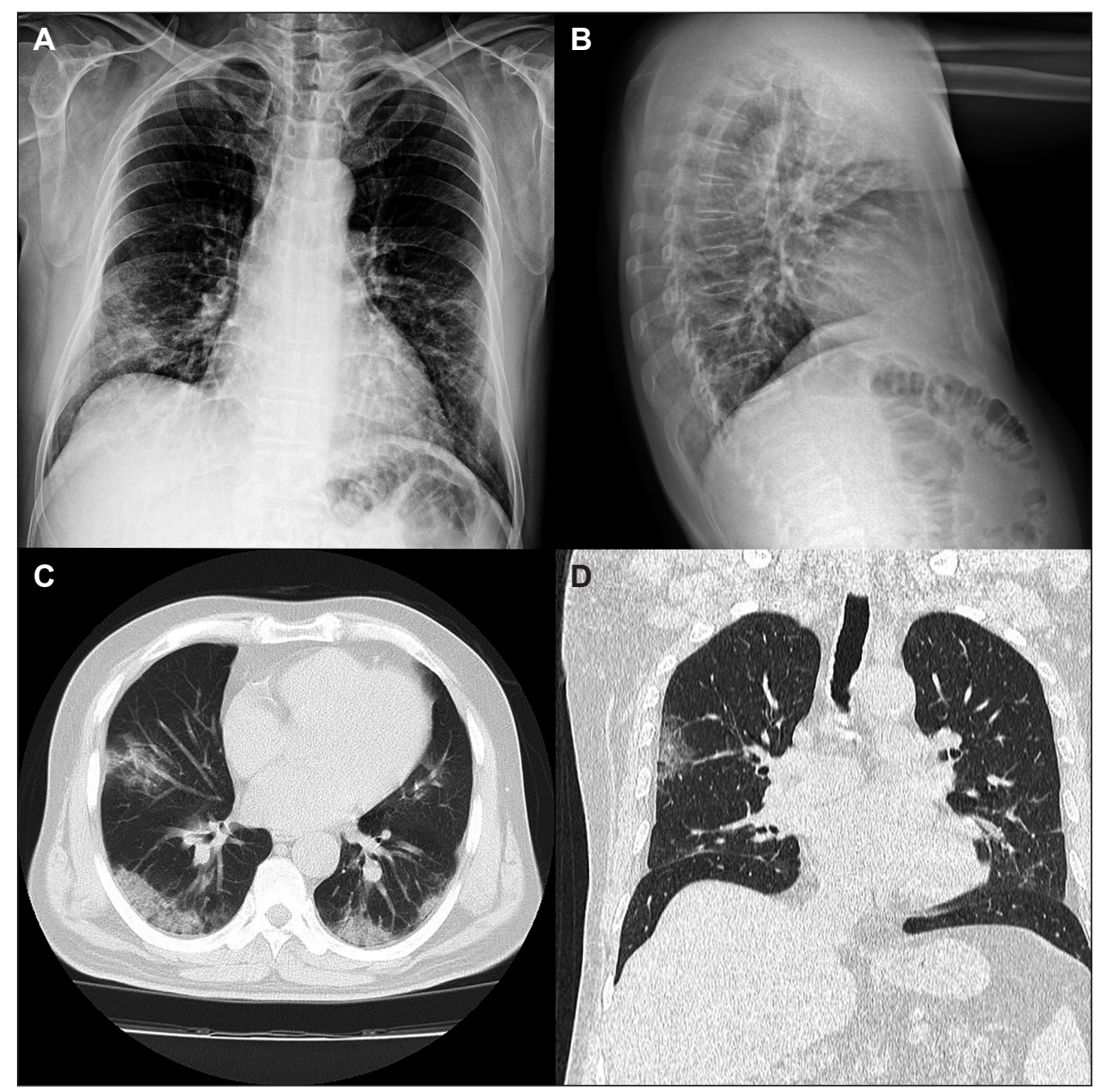

A. CXR Frontal. B. Lateral. Patchy peripheral opacities are seen at the lung fields mid to lower zones. C. CT Axial. D. Coronal. Bilateral multi-lobar peripheral ground-glass and consolidative opacities are seen in both lungs, mostly mid to lower zones. Non-specific mediastinal lymph nodes. Source/ Credit: Case courtesy of Dr Bahman Rasuli, $<$ a href="https://radiopaedia.org/" $>$ Radiopaedia.org $<$ / a $>$. From the case $<$ a href="https://radiopaedia.org/cases/75330">rID: $75330</ a>$. 
recommendations of the Italian Association of Ultrasonography in Medicine and Biology, and the Italian Association of Scientific Medical Societies and the Italian Image Society of Medical Radiology (SIRM, in Italian) about the use of radiological methods for COVID-19 as follow:

1. Chest X-Ray could be a first-line imaging tool that permits the first assessment of patients, especially in the emergency room, and in regions that $\mathrm{CT}$ does not exist. Also, it could differ the diagnosis toward other possible causes of pulmonary parenchymal involvement than COVID-19 infection [49].

2. CT as an additional tool that shows typical features of COVID pneumonia, which the most common is bilateral ground-glass opacities involving mainly the lower lobes [50].

3. Ultrasound of the lungs as a monitoring tool also to evaluate the effectiveness of pronesupination maneuvers [51].

4. SIRM recommends as high priority, to ensure appropriate sanitation procedures on the scanning equipment after detecting any suspected or positive COVID-19 patients, since the risk of spreading the infection into the $\mathrm{CT}$ room.

\section{The Point-of-Care Ultrasound (POCUS) Use}

In addition to the CRX and $\mathrm{CT}$, the most effective imaging methods used for COVID-19 also include the portable ultrasound (US), which has been tested and showed good results, especially for mitigating the risk of care takers contagion from Intensive Care Unit (ICU) patients. Ultrasound imaging can be an alternative method for chest imaging to follow up on COVID-19 pneumonia [52], as demonstrated in the case report from Italy [53]. Ultrasound can also distinguish between cardiogenic and noncardiogenic pulmonary edema [54] and can be deployed rapidly to exclude alternative causes of hypoxia in intensive care [55]. For consolidation, ultrasound has an accuracy of 97\% (sensitivity 93\%; specificity 93\%), compared with $75 \%$ for chest radiography (sensitivity 68\%; specificity $95 \%$ ) and $36 \%$ for auscultation (sensitivity $8 \%$; specificity $100 \%$ ) [54].

There are advantages in the use of US: the test is cheap, involves no ionizing radiation, and the results are available instantly. Compared to a portable X-Ray or CT machine, ultrasound

Figure 7. Portable CXR x CT in a patient with COVID-19 pneumonia.
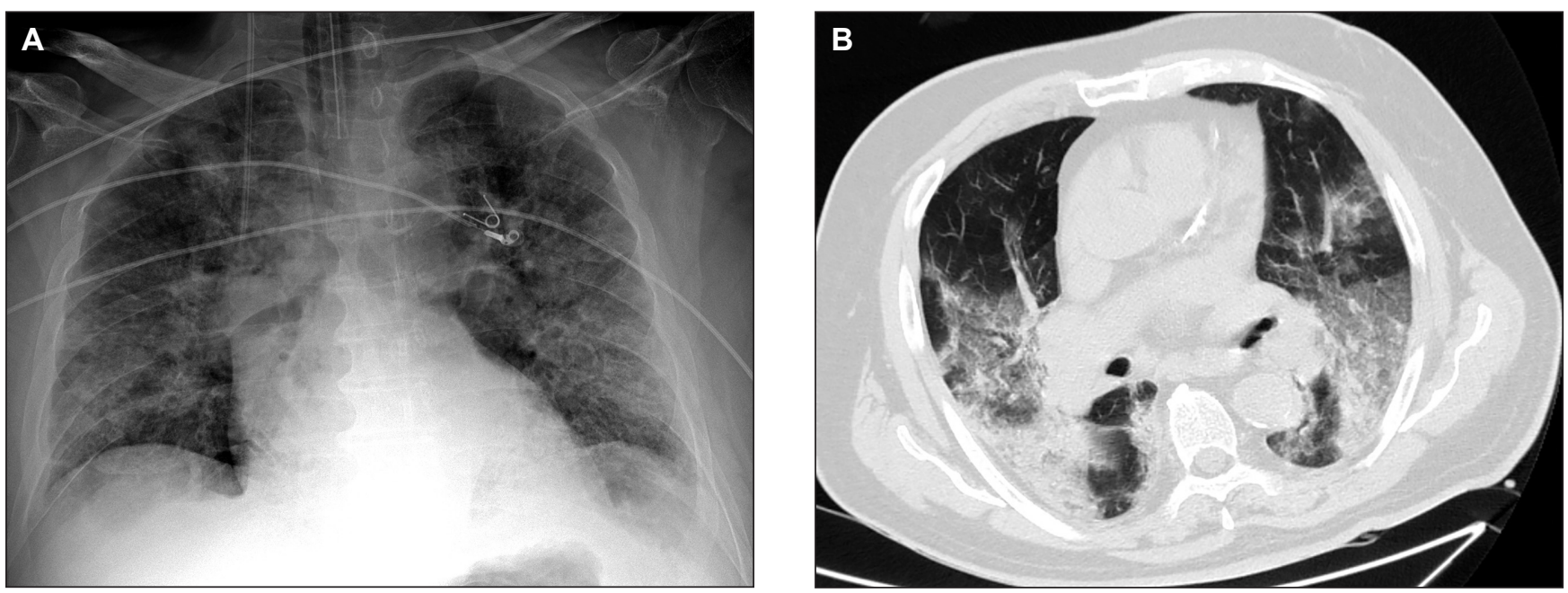

A. Portable CRX shows the presence of extensive bilateral ground-glass opacities as demonstrated on the recent CT. Also right IJV catheter and ETT noted. B. There are bilateral large areas of ground-glass opacities with crazy paving and, more evident at both bases, areas of consolidation. Enlarged mediastinal lymph nodes.

Source/Credit: Case courtesy of Dr Fabio Macori, $<$ a href="https://radiopaedia.org/">Radiopaedia.org $</ \mathrm{a}>$. From the case $<\mathrm{a}$ href="https:// radiopaedia.org/cases/74867">rID: $74867</ \mathrm{a}>$. 
machines are faster to decontaminate due to their small size. POCUS has a high sensitivity for the pulmonary manifestations of COVID-19, such as ARDS and consolidation. Furthermore, POCUS can be used to monitor treatment response. US is professional dependent, which means more training to have US as a method of choice especially in ICU $[56,57]$. Indeed, the main choice of POCUS is about the risk of contamination of healthcare staff, patients, and visitors when the patient is transferred to CT or CRX room.

\section{Conclusion}

Imaging methods to recognize indications of COVID-19 performs a critical role in the diagnosis and follow up of the patient with COVID-19 pneumonia. Despite CT having a better sensitivity when compared to CRX and ultrasound, the method brings a high risk of contamination to health professionals, visitors, room service, and staff of the hospital, as well as more ionization radiation for the patient. So, portable CRX and portable ultrasound could be a new tool with minimal risk of contamination and with good sensitivity. Currently, adding to the recommendation of CRX in the early stage, the $\mathrm{CT}$ is still preferable in the protocols to managing and diagnosing the patient with COVID-19 pneumonia.

\section{References}

1. $\mathrm{Hu} \mathrm{L}$, Wang C. Radiological role in the detection, diagnosis and monitoring for the coronavirus disease 2019 (COVID-19). Eur Rev Med Pharmacol Sci. 2020; 24(8): 4523-4528.

2. Shi H, Han X, Jiang N, Cao Y, Alwalid O, Gu J, Fan Y, Zheng C. Radiological findings from 81 patients with COVID-19 pneumonia in Wuhan, China: a descriptive study. Lancet Infect Dis 2020;20:425-434.

3. Xie X, Zhong Z, Zhao W, Zheng C, Wang F, Liu J. Chest CT for typical 2019-nCoV pneumonia: relationship to negative RT-PCR testing. Radiology 2020;200343.

4. Fang Y, Zhang H, Xie J, et al. Sensitivity of chest CT for COVID-19: comparison to RT-PCR. Radiology 2020:200432. Doi:10.1148/radiol.2020200432.

5. Song F, Shi N, Shan F, Zhang Z, Shen J, Lu H, Ling Y, Jiang Y, Shi Y. Emerging 2019 novel coronavirus (2019-nCoV) pneumonia. Radiology 2020;295:210-217.
6. Ai T, Yang Z, Hou H, Zhan C, Chen C, Lv W, Tao Q, Sun $\mathrm{Z}$, Xia L. Correlation of chest CT and RT-PCR testing in coronavirus disease 2019 (COVID-19) in China: a report of 1014 cases. Radiology 2020:200642.

7. Chung M, Bernheim A, Mei X, et al. CT imaging features of 2019 novel coronavirus (2019-nCoV). Radiology 2020:200230. Doi:10.1148/radiol.2020200230.

8. Xu X, Yu C, Qu J, Zhang L, Jiang S, et al. Imaging and clinical features of patients with 2019 novel coronavirus SARS-CoV-2. Eur J Nucl Med Mol Imaging 2020;47:12751280.

9. Pan $\mathrm{Y}$, Guan $\mathrm{H}$, Zhou S, et al. Initial CT findings and temporal changes in patients with the novel coronavirus pneumonia (2019-nCoV): a study of 63 patients in Wuhan, China. Eur Radiol 2020. Doi:10.1007/s00330-020-06731-x.

10. Pan F, Ye T, Sun P, Gui S, Liang B, Li L, Zheng D, Wang J, Hesketh RL, Yang L, Zheng C. Time course of lung changes on chest CT during recovery from 2019 novel coronavirus (COVID-19) pneumonia. Radiology 2020:200370.

11. Yoon SH, Lee K H, Kim JY, Lee YK, Ko H, Kim K H, Park $\mathrm{CM}$, Kim YH. Chest radiographic and CT findings of the 2019 Novel Coronavirus disease (COVID-19): analysis of nine patients treated in Korea. Korean J Radiol 2020;21:494500 .

12. Bernheim A, Mei X, Huang M, et al. Chest CT findings in coronavirus disease-19 (COVID-19): relationship to duration of infection. Radiology 2020:200463. Doi:10.1148/ radiol.2020200463.

13. Li W, Cui H, Li K, Fang Y, Li S. Chest computed tomography in children with COVID-19 respiratory infection. Pediatr Radiol 2020. Doi: 10.1007/ s00247-020-04656-7.

14. Xu YH, Dong JH, An WM, Lv XY, Yin XP, Zhang JZ, Dong L, Ma X, Zhang HJ, Gao BL. Clinical and computed tomographic imaging features of novel coronavirus pneumonia caused by SARS-CoV-2. J Infect 2020;80:394-400.

15. Yang W, Cao Q, Qin L, Wang X, Cheng Z, Pan A, Dai J, Sun Q, Zhao F, Qu J, Yan F. Clinical characteristics and imaging manifestations of the 2019 novel coronavirus disease (COVID-19): a multi-center study in Wenzhou city, Zhejiang, China. J Infect 2020;80:388-393.

16. Hu Z, Song C, Xu C, Jin G, Chen Y, Xu X, Ma H, Chen W, Lin Y, Zheng Y, Wang J, Hu Z, Yi Y, Shen H. Clinical characteristics of 24 asymptomatic infections with COVID-19 screened among close contacts in Nanjing, China. Sci China Life Sci 2020. Doi: 10.1007/ s11427-020-1661-4.

17. Cheng Z, Lu Y, Cao Q, Qin L, Pan Z, Yan F, Yang W. Clinical features and chest CT manifestations of Coronavirus disease 2019 (COVID-19) in a single-center study in Shanghai, China. AJR Am J Roentgenol 2020:1-6.

18. Xiong Y, Sun D, Liu Y, Fan Y, Zhao L, Li X, Zhu W. Clinical and high-resolution CT features of the COVID-19 infection: comparison of the initial and follow-up changes. Invest Radiol 2020. Doi: 10.1097/ RLI.0000000000000674.

19. Li Y, Xia L. Coronavirus disease 2019 (COVID-19): role of chest CT in diagnosis and management. AJR Am J Roentgenol 2020: 1-7. Doi: 10.2214/ AJR.20.22954.

20. Zhou S, Wang Y, Zhu T, Xia L. CT features of Coronavirus disease 2019 (COVID-19) pneumonia in 62 patients in Wuhan, China. AJR Am J Roentgenol 2020:1-8. Doi: 10.2214/AJR.20.22975. 
21. Han R, Huang L, Jiang H, Dong J, Peng H, Zhang D. Early clinical and CT manifestations of Coronavirus disease 2019 (COVID-19) pneumonia. AJR Am J Roentgenol 2020:1-6. Doi: 10.2214/ AJR.20.22961.

22. Xia W, Shao J, Guo Y, Peng X, Li Z, Hu D. Clinical and CT features in pediatric patients with COVID-19 infection: different points from adults. Pediatr Pulmonol 2020. Doi: https://Doi. org/10.1002/ppul.24718. 32)

23. Liu D, Li L, Wu X, Zheng D, Wang J, Yang L, Zheng C. Pregnancy and perinatal outcomes of women with Coronavirus disease (COVID-19) pneumonia: a preliminary analysis. AJR Am J Roentgenol 2020:1-6.

24. Zhao W, Zhong Z, Xie X, Yu Q, Liu J. Relation between chest $\mathrm{CT}$ findings and clinical conditions of coronavirus disease (COVID-19) pneumonia: a multicenter study. AJR Am J Roentgenol 2020:1-6.

25. Wang Y, Dong C, Hu Y, Li C, Ren Q, Zhang X, Shi H, Zhou M. Temporal changes of CT findings in 90 patients with COVID-19 pneumonia: a longitudinal study. Radiology 2020: 200843.

26. Dai WC, Zhang HW, Yu J, Xu H J, Chen H, Luo SP, Zhang H, Liang LH, Wu L, Lei Y, Lin F. CT Imaging and differential diagnosis of COVID-19. Can Assoc Radiol J 2020. Doi: 846537120913033.

27. Franquet T. Imaging of pulmonary viral pneumonia. Radiology 2011; 260: 18-39. 38) Hansell DM, Bankier AA, MacMahon H, McLoud T C, Muller N L, Remy J. Fleischner Society: glossary of terms for thoracic imaging. Radiology 2008;246:697-722.

28. Li M, Lei P, Zeng B, Li Z, Yu P, Fan B, Wang C, Li Z, Zhou J, Hu S, Liu H. Coronavirus disease (COVID-19): spectrum of CT findings and temporal progression of the disease. Academic Radiology 2020;27(5). https://doi.org/10.1016/j. acra.2020.03.003.

29. Simpson S, Kay FU, Abbara S, et al. Radiological Society of North America expert consensus statement on reporting chest CT findings related to COVID-19. Endorsed by the Society of Thoracic Radiology, the American College of Radiology, and RSNA. Radiol Cardiothorac Imaging 2020;2(2):e200152. https://Doi.org/ 10.1148/ ryct.2020200152.

30. Akçay Ş; Özlü T, Yilmaz A. Radiological approaches to COVID-19 pneumonia. Turk J Med Sci 2020;50:604-610. Doi:10.3906/sag-2004-160.

31. Bhat R, Hamid A, Kunin JR, Saboo SS, Batra K, Baruah D, Ambarish P. Chest Imaging in Patients Hospitalized With COVID-19 Infection - A Case Series. Current Problems in Diagnostic Radiology 2020:1-8. https://doi.org/10.1067/j. cpradiol.2020.04.001.

32. Zhang Z. High-resolution computed tomographic imaging disclosing COVID-19 pneumonia: A powerful tool in diagnosis. The British Infection Association: Journal of Infection 2020. https://Doi.org/10.1016/j.jinf.2020.03.047.

33. Kim JY, Ko JH, Kim Y, et al. Viral load kinetics of SARSCoV-2 infection in first two patients in Korea. J Korean Med Sci 2020; 35(7):e86.

34. Lin X, Gong Z, Xiao Z, et al. Novel coronavirus pneumonia outbreak in 2019: computed tomographic findings in two cases. Korean J Radiol 2020. Doi:10.3348/kjr.2020.0078.
35. Kanne JP. Chest CT findings in 2019 novel coronavirus (2019-nCoV) infections from Wuhan, China: key points for the radiologist. Radiology 2020:200-241. Doi:10.1148/ radiol.2020200241.

36. Lei J, Li J, Li X, et al. CT Imaging of the 2019 novel coronavirus (2019-nCoV) pneumonia. Radiology 2020; 295(1):200236. Doi:10.1148/radiol.2020200236.

37. Chan MS, Chan IY, Fung KH, Poon E, Yam LY, Lau KY. High-resolution CT findings in patients with severe acute respiratory syndrome: a pattern-based approach. AJR Am J Roentgenol 2004;182:49-56.

38. Rao TN, Paul N, Chung T, et al. Value of CT in assessing probable severe acute respiratory syndrome. AJR Am J Roentgenol 2003;181(2):317-319.

39. Caruso D, Zerunian M, Polici M, et al. Chest CT features of COVID-19 in Rome, Italy. Radiology 2020. Doi: 10.1148/ radiol.2020201237.

40. Zhang HW, Yu J, Xu HJ, et al. Corona virus international public health emergencies: implications for radiology management. Acad Radiol 2020;27(4):463-467.

41. Liu P, Tan XZ. 2019 novel coronavirus (2019-nCoV) pneumonia. Radiology 2020:200-257. Doi:10.1148/ radiol.2020200257.

42. Zhang Z Wang Y Y Chest CT manifestations of new coronavirus disease 2019 (COVID-19): a pictorial review. European Radiology 2020;10.

43. Tapé C, Byrd KM, Aung S, et al. COVID-19 in a Patient Presenting with Syncope and a Normal Chest X-Ray. Rhode Island Medical Journal 2013;103(3):50-51.

44. British Thoracic Radiology Society. CT Classification. 2020.

45. Wong HYF, Lam HYS, Fong AH-T, et al. Frequency and distribution of chest radiographic findings in COVID-19 positive patients. Radiology 2019:201160, https:// Doi. org/10.1148/radiol.2020201160.

46. Jacobi A, Chung M, Bernheim A, Eber C. Portable chest X-Ray in coronavirus disease-19 (COVID-19): A pictorial review. Clinical Imaging 2020;64:35-42. https://doi. org/10.1016/j.clinimag.2020.04.001.

47. ACR recommendations for the use of chest radiography and computed tomography (CT) for suspected COVID-19 infection|American College of Radiology. https:// www.acr. org/Advocacy-and-Economics/ACR-Position-Statements/ Recommendations-for-Chest-Radiography-and-CT-forSuspected-COVID19- Infection.

48. Neri E, Miele V, Coppola F, Grassi R. Use of CT and artificial intelligence in suspected or COVID-19 positive patients: statement of the Italian Society of Medical and Interventional Radiology. La Radiologia Medica 2020;29 April:202. https:// Doi.org/10.1007/s11547-020-01197-9.

49. https://www.sirm.org/wp-conte nt/uploa ds/2020/03/DICOVID -19-docum ento-inter societario.pdf.

50. Jiang F, Deng L, Zhang L, Cai Y, Cheung CW, Xia Z. Review of the clinical characteristics of Coronavirus Disease 2019 (COVID-19). J Gen Intern Med 2020. https://doi.org/10.1007/ s1160 6-020-05762 -w.

51. Pontet J, Yic C, Díaz-Gómez JL, Rodriguez P, Sviridenko I, Méndez D, Noveri S, Soca A, Cancela M. Impact of an ultrasound-driven diagnostic protocol at early intensivecare stay: a randomized-controlled trial. Ultrasound J 2019;11(1):24. https://doi. org/10.1186/s1308 9-019-0139-2. 
52. Reali F, Sferrazza Papa G F, Carlucci P, Fracasso P, Di Marco F, Mandelli M, Soldi S, Riva E, Centanni S. Can lung ultrasound replace chest radiography for the diagnosis of pneumonia in hospitalized children? Respiration 2014;88:112-115.

53. Buonsenso D, Piano A, Raffaelli F, Bonadia N, de Gaetano Donati K, Franceschi F. Point-of-care lung ultrasound findings in novel coronavirus disease-19 pnemoniae: a case report and potential applications during COVID-19 outbreak. Eur Rev Med Pharmacol Sci 2020;24:27762780 .

54 Copetti R, Soldati G, Copetti P. Chest sonography: a useful tool to differentiate acute cardiogenic pulmonary edema from acute respiratory distress syndrome (ARDS). Cardiovasc Ultrasound 2020;6:16.
55. Sekiguchi H, Schenck LA, Horie R, et al. Critical care ultrasonography differentiates ARDS, pulmonary edema, and other causes in the early course of acute hypoxemic respiratory failure. Chest 2015;148:912-8.

56. Vetrugno L, Bove T, Orso D, Barbariol F, Bassi F, Boero E, Ferrari G, Kong R. Our Italian experience using lung ultrasound for identification, grading and serial follow-up of severity of lung involvement for management of patients with COVID-19. Echocardiography 2020;37:625-627. Doi: 10.1111/echo.14664.

57. Peng QY, Wang XT, Zhang LN. Findings of lung ultrasonography of novel corona virus pneumonia during the 2019-2020 epidemic. Intensive Care Medicine 2020;Mar 12. Doi: 10.1007/s00134-020-05996-6. 